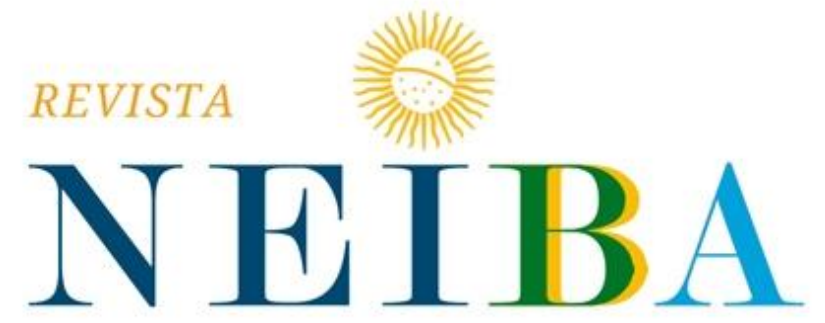

CADERNOS ARGENTINA-BRASIL
Volume 8, 2019, p. 01-15

DOI: 10.12957/neiba.2019.43343 | e43343 | ISSN: 2317-3459

\title{
CABO VERDE E BRASIL: A CHAVE DO ATLÂNTICO SUL
}

CAPE VERDE: KEY TO BRAZIL IN ATLANTIC OCEAN

\section{Danilo Avellar Bragança ${ }^{1}$}

'Universidade Federal Fluminense (UFF), Niterói, Rio de Janeiro, Brasil. E-mail: dbraganca@id.uff.br. ORCID: 0000-0002-9503-6019.

Recebido em: 14 jun. 2019 | Aceito em: 30 nov. 2019 
RESUMO

O seguinte texto é um exercício de descrição analítica sobre Cabo Verde e as relações já existentes entre o país africano e o Brasil, em suas múltiplas continuações. O Atlântico Sul é área-chave para a projeção internacional brasileira e as relações com os países lindeiros em África têm sido alvo de políticas públicas importantes, mas são feitas de forma intermitente. Nesse momento, é possível dizer que há certa retração na aproximação do Brasil e dos países africanos parceiros da costa atlântica. Assim, a ideia é usar o exemplo cabo-verdiano para explorar as potencialidades brasileiras na região, além de trazer luz à sua história e trajetória política recente, pouco conhecida da maior parte do público acadêmico brasileiro.

Palavras-chave: Cabo Verde; política externa brasileira; diplomacia; geopolítica; África.

\section{ABSTRACT}

The following text is an analytical description exercise on Cape Verde and the relationship between the African country and Brazil, in its multiple continuations. The South Atlantic is key area for Brazilian international projection and relations with the nearby countries in Africa have been the target of important public policies, but are made intermittently. At this point, it is possible to say that there is a certain retraction in the approximation of Brazil and the African countries on the Atlantic coast. Thus, the idea is to use the Cape Verdean example to explore the Brazilian potentialities in the region, and bring light to its recent history and political trajectory, little known to most of the Brazilian academic public.

Keywords: Cape Verde; Brazilian foreign policy; diplomacy; geopolitics; Africa.

\section{INTRODUÇÃO}

Esse texto tem o objetivo de discutir importante papel de Cabo Verde na geopolítica do Atlântico e que aqui no Brasil costumamos desconsiderar. Cabo Verde é um arquipélago que está a menos de $600 \mathrm{~km}$ da costa atlântica africana, é parte de nosso entorno estratégico e de nossos interesses no sistema internacional. Cabo Verde é um antigo entreposto comercial português, que com o Brasil guarda semelhanças importantes e, por sua posição privilegiada, pode contemplar parte destes interesses no Atlântico Sul. A hipótese principal aqui é que a proximidade cultural e vantagem geoestratégica garantiriam melhor comunicação diplomática e política se Cabo Verde fizesse parte indissociável de toda esta equação. 
Assim, este texto parte de alguns debates importantes que mostram nosso desconhecimento e a nossa incapacidade de produzir coerência em nossa política externa para a África. Desdobra-se breve debate histórico e leitura bibliográfica, apresentando a história internacional de Cabo Verde, em suas relações com outros países, dentro e fora da empresa colonial. O status de departamento relativamente autônomo dado a Cabo Verde por Portugal garantiu-lhe uma possibilidade mais ampla de parceiros internacionais, garantindo-Ihe relativa autonomia e inserção internacional.

Depois desse debate histórico, o texto se desenvolve numa breve apresentação cultural do país sua relação com a lusofonia e com o Brasil especificamente. Usa-se aqui metodologia simples, que aproveitaram as fontes privilegiadas que foram acessadas. Essas fontes vieram de um convênio da Fundação Getúlio Vargas, através do Centro de Pesquisa e Documentação (CPDOC) e o Instituto Pedro Pires para a Liderança (IPPPL), sediado em Praia $^{2}$. O acesso a este tipo de documento, pessoal, amealhado pela família e assessores, nestes anos todos da história do comandante Pedro Pires e sua trajetória política, garante a possibilidade de novas perspectivas sobre o tema.

\section{HISTÓRIA E CULTURA DE CABO VERDE E RELAÇÕES INTERNACIONAIS}

Cabo Verde é antes de mais nada um formidável ponto geoestratégico. As ilhas do arquipélago estão localizadas a oeste do Senegal, na costa atlântica africana. Tem proximidade com o continente, mas sua dispersão territorial apresenta dificuldades importantes na articulação e desenvolvimento do país. A navegação é algo fundamental e necessário, e o potencial a ser explorado nas ilhas é enorme.

Até o século XVI, Cabo Verde era um arquipélago desabitado. A presença de fenícios, navegadores árabes e pescadores africanos na região era esporádica. A ilha do Fogo e seu vulcão ativo certamente chamara a atenção de alguns navegadores, mas que nunca se estabeleceram na região de forma definitiva até que os portugueses o fizessem, a partir de 1450. Ou seja, antes do desembarque no Brasil, a lógica da empreitada colonial portuguesa já havia rastreado a costa africana em busca de negócios. Em menos de 30 anos, toda a empresa escravagista portuguesa estava instalada, e Cabo Verde passou a ser apoio estratégico no controle das feitorias estabelecidas.

\footnotetext{
2 Esse texto é resultado um projeto realizado na Fundação Getúlio Vargas junto ao Professor Celso Castro e sua equipe, que tem como objetivo final uma entrevista com o ex-presidente de Cabo Verde Pedro Pires, a ser posteriormente transformado em acervo do Centro de Pesquisa e Documentação da Fundação Getúlio Vargas (CPDOC).
} 
Mais que isso. Cabo Verde passou a ser passagem para navios de muitas nacionalidades, inclusive tendo visto passar por seus portos navegadores como Colombo e Vasco da Gama. A posição geográfica privilegiada fez o arquipélago ser habitado, politicamente administrado de forma embrionária, em modelo que depois seria utilizado sem sucesso no Brasil e em outras administrações portuguesas. Faltava aos portugueses, no entanto, senso de proporcionalidade. Se as ilhas cabo-verdianas foram administradas pela Coroa a partir de capitanias, a exemplo do que aconteceu em territórios na costa, como em Angola e Moçambique, este exemplo foi transposto para o Brasil e implantado quase cem anos depois, se mostrando logo ineficaz.

Cabo Verde também foi precursora na formação da empresa açucareira no Brasil. O plantio foi considerado um sucesso em terras secas como aquelas experimentadas pelo Nordeste brasileiro, e há relatos das primeiras mudas terem sido transplantadas da ilha para o país. Diz o diplomata cabo-verdiano no Brasil, Daniel António Pereira:

“O 'negro cabo verde', por exemplo, era aquele que dominava a técnica da aguardente (a cachaça brasileira) e tinha rudimentos da panaria, artes e ofícios aprendidos, primeiro, no laboratório humano da Ribeira Grande, hoje Cidade Velha, localizado no sul da Ilha de Santiago, e depois na Praia de Santa Maria da mesma ilha, hoje capital do meu país, Cabo Verde." (p.52)

Desde então, o arquipélago foi cobiçado permanentemente por potências estrangeiras. Da costa do Senegal, forças francesas atacavam Cabo Verde, contando com resistência portuguesa. Cabo Verde foi envolvido no conflito luso-espanhol pela sucessão de Castela, entre 1475 e 1479, com um ataque de 25 navios e captura de Antonio de Noli, navegador italiano que é um dos pioneiros no arquipélago. As hostilidades cessaram, e o domínio português sobre os Açores, a Madeira e Cabo Verde foi sacramentado pelo Tratado de Alcáçovas-Toledo, de 1480.

É a partir da Paz de Alcáçovas que as primeiras regras do convívio expansionista de Espanha e Portugal foram definidas. Portugal manteria o controle de toda a costa da Guiné e da Mina, interessado na manutenção de certo domínio sobre o Atlântico Sul, onde Cabo Verde teria posição fundamental. Os reis berberes de Fez também se subordinariam ao controle luso, garantindo exclusividade de navegação portuguesa aos territórios já conquistados e o impedimento da navegação espanhola por estas áreas. 0 Atlântico Sul ficaria dividido em duas esferas de influência, compartilhado entre Portugal e Espanha, que se estabeleceria nas Ilhas Canárias. O domínio português, no entanto, seria inegável. O Tratado de Alcáçovas garantiria inclusive que os infantes espanhóis seriam criados em território português, até alcançarem idade adulta. É 
preciso entender de que forma compartilhar este oceano com outras potências e a História é um elemento importante nessa condição.

O controle das ilhas atlânticas por Portugal the garantiu o sucesso inesperado, porém pouco duradouro sobre o Atlântico. Diz-se pouco duradouro porque Portugal logo seria suplantado em força política, econômica e estratégica pela Espanha e por outras potências estrangeiras. Mas isto não condiz com a presença maciça da empresa portuguesa e de seus agentes, o que garantiu a influência cultural portuguesa e, por conseguinte, brasileira, por todos os territórios conquistados.

A partir disso, todo o desenvolvimento da indústria escravagista tinha como posto importante o Porto de Praia, em Cabo Verde. A presença portuguesa, mais o cosmopolitismo que a geografia garantira a Cabo Verde, adicionado ao elemento africano, formou um profundo sentido de identidade exclusiva de um povo exógeno dali, mas que se estabeleceu e definiu as ilhas do arquipélago como sua casa. A cultura crioula cabo-verdiana encontra pouco paralelo, seja na musicalidade, na comida, nos costumes.

A partir da Revolução Industrial e da inserção britânica na sua própria empresa imperial, esse composto cultural-demográfico ganharia mais um componente. O comércio triangular, do rum, dos escravos e da matéria-prima das colônias americanas daria lugar a uma dominação comercial monopolista por parte da Inglaterra. Um complexo sistema em forma de um triângulo foi substituído pela presença marcante dos produtos ingleses e grande influxo de matérias-primas que as indústrias inglesas consumiam e comercializavam em toda a parte do mundo.

Em 1578, o navegador inglês Francis Drake invade as ilhas de Cabo Verde, sendo parado pela resistência local, formada majoritariamente por escravos. Durante todos os anos da União Ibérica (1580-1640), espanhóis e ingleses atacaram o arquipélago, e em menor escala, navegadores holandeses, assim como fizeram no Nordeste brasileiro. Mesmo com a imposição portuguesa de 1591 proibindo estrangeiros de comercializar em Cabo Verde, a presença de navegadores europeus de muitas nacionalidades era comum, proporcional à explosão da empresa escravagista e aos objetivos das outras potências do continente.

A administração da costa portuguesa na África era feita de Cabo Verde, por conta precisamente de sua posição. Entre 1650 e 1670, cerca de 150 mil escravos foram levados para o Brasil, e este número aumentou profundamente nas décadas seguintes, sobretudo para serviço de mão-de-obra no nordeste açucareiro. A economia caboverdiana era inteiramente dependente das províncias do Pará e do Maranhão, 
chegando a administrar efetivamente o arquipélago a partir de 1757, até o ano de 1778.

A relação entre Brasil e Cabo Verde é, portanto, muito antiga e muito próxima, sobretudo com o Norte-Nordeste. Ainda que subordinada neste primeiro momento à lógica colonial portuguesa, muito cedo a proeminência econômica do Brasil serviria de força de atração para a sobrevivência das ilhas. Com Marques de Pombal e suas reformas liberais, a diminuição do Estado português garantiria uma ainda maior relação, cada vez menos subordinada ao pacto colonial, mas certamente dependente do exterior para a sobrevivência de Cabo Verde.

No início do século XIX, as grandes potências europeias começam a abolir a escravidão. Cabo Verde passa a receber um influxo muito grande de degredados portugueses enviados por Lisboa, e o arquipélago passa receber atenção ainda maior por sua importância no tráfico negreiro. Ataques ingleses se intensificam na região caboverdiana, e o novo elemento da vez é a presença estadunidense, com a abertura do primeiro consulado do país em Cabo Verde em 1818. As potências mundiais sempre estiveram ali, ao contrário da condição relativamente pacífica que se admite sobre o Atlântico Sul. As guerras napoleônicas forçaram a migração da capital do império português de Lisboa para o Rio de Janeiro, e o tratado anglo-português continha cláusula secreta transferindo pontos do império português na costa africana para a administração inglesa, sobretudo Cacheu e Bissau, por cinquenta anos.

Um povo acostumado com a necessidade do trânsito interno entre as ilhas passou também a se acostumar com a diáspora definitiva, com a fuga de uma condição inexoravelmente flagelada. Há registros de cabo-verdianos na Inglaterra já no fim do século XVII, e a grande comunidade cabo-verdiana nos Estados Unidos teve seu start em 1824, com a primeira naturalização. A diáspora é um elemento fundamental neste país, parte de sua identidade e origem.

A independência do Brasil em 1822 teve um grande impacto em toda a costa da Guiné assim como em todo império português, impacto que já vinha sendo sentido desde 1807, na verdade, em toda África. Os dois primeiros reis que reconheceram a independência eram do Benin e de Lagos, atual Nigéria. Correu pelas colônias portuguesas a intenção de se desanexarem de Portugal tal como fizera o Brasil e se anexarem ao próprio Brasil. O imbróglio entre Brasil e Portugal sobre as possessões africanas não seria inteiramente resolvido, mas os laços que se desapertaram entre os países criaram outros ainda mais importantes com Angola, Moçambique e Cabo Verde. O reconhecimento formal da independência brasileira só foi alcançado em 1825, depois de manifestação expressa do Brasil de que não haveriam aventuras de nossa burguesia 
na ocupação de Cabo Verde e Angola, pontos fundamentais da empresa escravagista e ainda mais fundamentais para a manutenção da economia brasileira.

Havia, entretanto, a presença inglesa. As aspirações tanto de brasileiros quanto de portugueses na manutenção e expansão de suas possessões e do lucrativo tráfico negreiro esbarraria sobremaneira nas definições antiescravidão vindas da Grã-Bretanha e sua altivez na Costa da Guiné. Todos estes movimentos legais culminam na promulgação da Lei Eusébio de Queirós, em 1850, que proibiria o tráfico intercontinental. Já desde Lorde Palmerston se aventava aos ingleses o direito de abordar qualquer navio suspeito de carga ilegal, além de intensa pressão política e diplomática. Ingleses participaram diretamente em levantes de escravos em Cabo Verde e na libertação de muitos outros cativos sob domínio da igreja e da Coroa portuguesa.

Diz Pereira (2015):

Mas o principal obstáculo à exploração econômica da África, para Portugal, e para qualquer outras potências coloniais, sem excluir a Grã-Bretanha, estava na solidez das estruturas pré-existentes, na vitalidade do tráfico de escravos, no poder dos negociantes negreiros, que resistiam à penetração externa, numa primeira fase opondo-se à transição para o comércio "lícito" e num segundo momento, procurando controlar essa transição a seu favor. (2015, p. 73).

Além disso, os Estados Unidos também passaram a combater a empresa escravagista. Em 1819 foi estabelecido o chamado Africa Squadron. A Marinha estadunidense envolveria-se em outros esquadrões, no Atlântico Sul e no próprio Brasil, empregando esquadra de cruzadores, muitas vezes em conjunto com a Marinha britânica, com o chamado West Africa Squadron. Os britânicos se basearam em Serra Leoa, enquanto boa parte da frota do Africa Squadron estava sediada em Praia, Cabo Verde. O primeiro comandante da esquadra estadunidense na costa da Guiné foi o Comodoro Matthew Perry, figura importante na abertura do Japão posteriormente, e este ficava sediado também em Cabo Verde.

As esferas de influência, outrora pertencentes a Portugal e Espanha, passaram a ser compartilhadas pela já estabelecida Marinha britânica e pela Marinha estadunidense em expansão. As péssimas condições em Cabo Verde foram empecilho importante para o sucesso do Africa Squadron, muito mal equipado e com pouco retorno na captura de escravos e navios negreiros. Comandantes dessa esquadra eram, eles mesmo, donos de escravos, o que sugere corrupção. Sobre a presença do Africa Squadron, afirma Meintel (2002):

When the Africa Squadron under Commodore Matthew Perry (later to become renowned for opening Japan to Westerners), arrived in Cabo Verde in 1842 the Americans benefitted from the good will generated by gifts of food sent from 
the United States during the famine of 1830-33 that had caused some 30,000 deaths. Fund-raising campaigns throughout New England had brought tens of thousands of dollars worth of contributions of food and money collected in churches and schools, and from the wider public. Relief vessels laden with food were sent to the Cape Verdes, an experience that was repeated when drought struck again in the mid-1850s. (Meintel 2002, p. 20).

\section{1 - A SEGUNDA FASE DA OCUPAÇÃO COLONIAL E O SÉCULO XX}

O apoio estadunidense foi fundamental e, ainda que articulado com interesses comerciais, formou um laço cultural ainda existente entre os dois países. Um dos efeitos principais dessa presença anglo-americana no atlântico Sul e das apreensões foi a escassez de escravos nos Estados Unidos e Brasil, dois dos grandes compradores. 0 preço subiu abruptamente e o tráfico ilegal ainda era bastante vantajoso, sobretudo facilitado por agentes públicos britânicos e dos Estados Unidos. O Africa Squadron é desmontado em 1861, às margens da guerra civil americana, com seus navios sendo utilizado para bloquear portos escravagistas ao sul dos Estados Unidos, sob tutela de Abraham Lincoln.

O Congresso de Berlim (1884-1885) marca um outro elemento importante, e que reforça a posição estratégica de Cabo Verde. França e Inglaterra tiveram forte protagonismo, mas reclamos no território africano também foram feitos por Portugal, Alemanha, Espanha, Itália e Bélgica.

A longa administração conjunta de Cabo Verde e da Guiné portuguesa foi extinta em 1879 e duas entidades coloniais separadas foram consolidadas em Berlim. A presença britânica em Bolama e os reclamos portugueses foram adjudicados em mediação internacional pelo presidente estadunidense Ulysses Grant, decidindo em favor de Portugal. Não foram raros os eventos de amotinados, revoltosos e levantes contra a presença estrangeira em Cabo Verde, sumariamente contidos por forças de pacificação ordenadas por Portugal.

A encruzilhada das rotas do Atlântico teria, no entanto, tratamento levemente diferenciado. Em âmbito administrativo, Portugal tratava Cabo Verde como distrito autônomo, em posição semelhante ao que faz com Açores e llha da Madeira. Este é um debate que ainda hoje permanece ainda em Portugal, como reminiscências do antigo império ultramarino português. O salazarismo representaria uma ruptura importante na ordem institucional portuguesa, mas sem efeitos diretos na relação colonial com as ilhas e as colônias portuguesas. A presença talvez fosse ainda mais sentida. 
O costume de usar as ilhas como destino para degredados, como alguns participantes da Inconfidência Mineira em 1789, foi reutilizado para servir na construção da prisão do Tarrafal, em 1949, para opositores políticos do regime de Salazar. Se o fluxo de chegados às ilhas é enorme, o dos que as deixam é ainda mais significativo, e sugere a relação de Cabo Verde como passagem, sobretudo nestes tempos. A diáspora interna, fugindo da seca, da fome, do domínio estrangeiro, é articulada a uma diáspora externa, com a dispersão de muitos cabo-verdianos por muitas partes do mundo. O número de cabo-verdianos residindo no exterior é superior ao dos que residem nas ilhas, certamente uma condição sui generis para o país e sua sociedade. Praticamente o dobro. Fala-se em comunidade transnacionalizada não-localizada, em fuga de cérebros dos mais jovens cabo-verdianos que não se formam em seu país, mas nas universidades d'além-mar. Uma diáspora intelectual que afeta em muito os rumos do país.

É do exterior que brota o PAIGC (Partido Africano pela Independência da Guiné e de Cabo Verde), movimento criado por Amilcar Cabral, libertador da Guiné-Bissau, e que tem importância central na independência de Cabo Verde, em 1975. Desde então, as pontes criadas no exterior servem de horizonte de possibilidades para 0 desenvolvimento autônomo do país. Pretende-se, desde o começo, uma Cabo Verde global, aproveitando seu potencial natural. É da essência de Cabo Verde ser rota, com o privilégio da localização, o meio do Atlântico. É da essência de Cabo Verde ser global.

Para isso, toda uma rede de atuação internacional foi montada como política de Estado, mudada governo a governo, desde a sua independência. Há representações caboverdianas em países importantes, como Angola, Moçambique, Brasil, Alemanha, Estados Unidos, China, Cuba, Itália, Senegal e Portugal. Autoridades cabo-verdianas visitam permanentemente estas legações diplomáticas, buscando para seus cidadãos acordos de segurança social nos países destino. São também importantes as associações de cidadãos cabo-verdianos nestes países, sobretudo na numerosa comunidade nos Estados Unidos, que inclusive gozam de influência política considerável nos dois países. A recém-criada Universidade de Cabo Verde vem formando quadros importantes preocupados com o estudo da diáspora, ultrapassando a visão majoritária centrada na importância das remessas financeiras, e chegando à condição de comunidades políticas cabo-verdianas difusas. Estas possuem grande representatividade, como a de Portugal e Estados Unidos novamente.

Tudo isso se soma a uma condição também rara em África, que é a estabilidade política. Da independência até 1991, o país foi governado em regime de partido único, isto sim bastante comum em África. Com o fim da Guerra Fria, o desmantelamento da União Soviética e a desarticulação dos vários serviços que prestava à países em desenvolvimento, sobretudo formação e apoio financeiro, o regime unipartidário se 
dissolveu e foi aberto. Eleições foram realizadas e o partido dominante, o PAIGC, foi derrotado de forma contundente pelo Movimento pela Democracia (MpD). A partir de então, as eleições transcorreram sem maiores problemas, inclusive com o retorno do PAICV ao poder, eleito com Pedro Verona Pires, um de seus fundadores e libertador nacional.

Diz Tavares (2013):

\begin{abstract}
Parece até um paradoxo, que Cabo Verde, na altura da sua independência, considerado um dos países mais pobres do mundo devido às suas vulnerabilidades econômicas e naturais e havendo um certo ceticismo sobre a sua viabilidade, tenha acabado por se tornar um dos países mais viáveis e consolidados da África. Isso chama atenção ao passo que muitos dos países que, a priori, mostravam maior viabilidade, por terem recursos naturais, encontram-se hoje muito abaixo de Cabo Verde no Ranking do Desenvolvimento Humano (ONU, 2009) (Tavares 2009, p. 220).
\end{abstract}

\title{
2 - AS RELAÇÕES COM O BRASIL E COM A CPLP
}

A democracia em Cabo Verde é algo consolidado, a despeito da instabilidade que assombra o continente africano. As instituições são fortes, os poderes são divididos. Um dos países que mais recebe ajuda internacional em todo o mundo consegue administrar bem esse apoio, mesmo a despeito dos problemas estruturais que o país sempre irá apresentar. São fortes as instituições socioculturais, e o país tem uma tradição cultural importante que tenta resgatar, apesar das incertezas sobre sua origem e relação cultural - falta aos cabo-verdianos entenderem se são africanos, portugueses, expátridas.

A vocação comercial de Cabo Verde traz eventualmente problemas importantes. Cabo Verde é importante rota de passagem de traficantes de toda sorte, de gente e de drogas. É como um hub, já consolidado para outros fins como a aviação civil. Cabo Verde funciona como um entreposto de reabastecimento, descanso, passagem e estadia.

A defesa e segurança em Cabo Verde são, portanto, temas fundamentais. Países da região são beneficiados com políticas eficientes de melhoria dos recursos caboverdianos, enquanto parcerias especiais, com o Brasil, com a China, com países africanos e com a União Europeia, tem dotado Cabo Verde de possibilidades melhores. O controle da vasta massa marítima que cerca Cabo Verde é objetivo central, o que geopoliticamente sempre representou presença maciça no Atlântico Sul. Cabo Verde é vulnerável e mesmo o relativo desenvolvimento dos últimos anos não Ihe garantirá autonomia e a articulação internacional torna-se de novo imperativa. 
A presença brasileira poderia se dar de forma mais consistente. Não é que nos anos dos governos Lula da Silva e Rousseff isto não tenha acontecido. Foram realizados muitos acordos de cooperação, que hoje são politicamente questionados, sem, no entanto, que estas críticas tenham valor prático. A Agência Brasileira de Cooperação $(A B C)$ é a principal entidade que articula esses acordos, estendendo-se de áreas fundamentais para o desenvolvimento de Cabo Verde e da aproximação com o Brasil.

Na Educação, por exemplo, o Ministério da Educação (MEC) do Brasil e a Coordenação de Aperfeiçoamento de Pessoal de Nível Superior (CAPES) se destacam nessa função. A Universidade da Integração Internacional da Lusofonia Afro-Brasileira (UNILAB) é um exemplo importante dessa atuação. Em Cabo Verde, especificamente, o apoio brasileiro pendula de apoio à criação de institutos censitários, apoio no programa de alimentação nas escolas, o apoio da Pastoral da Criança, gestão de patrimônio cultural, incentivo à horticultura, formação e treinamento de pessoal para o Ministério do Trabalho e Solidariedade de Cabo Verde, criação de um Data Center, além de apoio de ensino técnico militar (IPEA, 2014).

Mas a preocupação brasileira não é recente. A relação do Brasil com os chamados PALOP (Países Africanos de Língua Portuguesa) data do início de suas existências independentes, o fim da década de 1970. A despeito das relações privilegiadas com Portugal, o governo Geisel empreendeu política de diversificação de embaixadas, num total de 14 novas, inclusive Cabo Verde. A política de não-militarização do Atlântico Sul, de Geisel e depois Figueiredo, foi tocada com relativo sucesso. O Itamaraty criaria nova subdivisão, para a África, dando lugar a diplomatas voltados especificamente para uma política africana.

Com José Sarney, já em 1985, o Brasil lança a chamada Zopacas (Zona de Paz e Cooperação do Atlântico Sul). Sarney esteve em Cabo Verde. Já o sucessor Fernando Collor de Mello não deu sequência à diplomacia sul-sul, só retomada de forma muito tímida com Fernando Henrique Cardoso, após 1995. Essa timidez foi rompida de certa forma pela atuação do chanceler Lampreia no reconhecimento da importância da Comunidade de Países de Língua Portuguesa (CPLP).

Diz Saraiva (2002):

A África ficou fora do norte da política externa do Brasil nos anos 1990. O Brasil se deixou contaminar pela interpretação ingênua das relações internacionais kantianas, em torno das quais as saídas para a modernidade estavam no multilateralismo e no esforço da construção de uma agenda global consensual e na regulação de temas globais como o liberalismo econômico, o meio ambiente, os direitos humanos, entre outros. Essa confusão conceitual levou ao abandono de ricos caminhos anteriores já trilhados pelo Brasil na África, 
emanados pelo modelo de substituição de importações e da política de promoção de exportações. (Saraiva 2002, p. 45).

A política externa brasileira para os países africanos era feita sobretudo entre a década de 1990 e os anos de 2002 a partir de impulsos, diferente da continuidade que anteriormente se havia observado com Jânio Quadros Santiago Dantas e Afonso Arinos de Melo Franco (Lechini, 2003). A Política Externa Independente, algo simbólico do período, não teve os seus patamares retomados na década de 90.

Há fatores importantes na África também que podem explicar esse relativo distanciamento. Os anos 90 foram extremamente violentos no continente, e uma melhor coordenação entre os países africanos e potências estrangeiras possibilitou a introdução as coisas a redução da violência armada, a estabilidade política e a reaproximação com o mundo. Os esforços de integração do continente africano também são emblemáticos desse momento. Economicamente, África sofreu um grande salto de industrialização e urbanização durante a década de 90 e a criação da União africana em 2003 garantiram uma nova condição de cooperação continental que se baseava fundamentalmente os aspectos militares e de segurança, temas muito caros para África. É uma construção importante o da associação entre segurança e desenvolvimento. É quase como uma tomada de consciência de que não há um sem o outro.

A construção da Comunidade de Países de Língua Portuguesa em 1996 tentativas mais contundentes de aproximação entre o Mercosul e blocos econômicos na África austral com especial interesse na África do Sul são bastante tímidos, mas certamente servem como incentivo para fora os mais importantes e ainda em funcionamento hoje como foro Índia Brasil e África do Sul (IBAS).

As Forças Armadas brasileiras são fundamentais nessa aproximação que se acentua na década dos anos 2000, mas já tem alguns esboços nos anos 90. O projeto de desenvolvimento da aula naval da força de defesa da Namíbia é um exemplo clássico mais em 2005 a costa de Cabo Verde foi terreno de exercícios militares com participação brasileira.

\section{CONCLUSÃO}

O papel da África na política externa brasileira é sempre um tema pouco linear. É incomum que o nível de atenção dados pela opinião pública, pela elite produtiva e pelos setores político-burocráticos seja o mesmo, dependendo da troca de governo ou da correlação de forças. São raros os momentos em que a África fica distante inteiramente 
da nossa ação diplomática, mas num momento como esse, a África parece relegada a um ponto bem pequeno do nosso elenco de objetivos internacionais.

Não deveria ser assim. A África se abriu ao Brasil um processo paralelo ao fim do colonialismo e à libertação colonial. Estava ali prescrito um campo bastante promissor para as empresas nacionais e para projeção internacional do Brasil. Desde 1961 nossos acadêmicos demonstravam o interesse na África e é seminal o trabalho de José Honório Rodrigues literalmente intitulado Brasil e África: Um outro horizonte.

A importância dada à África pelo acadêmico brasileiro é fundamental no resgate dessa compreensão de que as relações com Cabo Verde são fundamentais para as pretensões políticas do país, sempre solapadas por crises de muitas naturezas. Sobre isso, diz Zamparoni (1995):

\footnotetext{
No que tange à África, o primeiro autor brasileiro francamente anti-colonialista foi José Honório Rodrigues. As relações entre Brasil e África são analisadas numa perspectiva histórica, sem mistificações ou preconceitos. Sua obra coincide com o desencadear da luta armada de libertação nacional na GuinéBissau e Angola e com a chamada política externa independente levada a cabo pelo governo Jânio Quadros. É deste mesmo período a criação de três centros de estudos africanos existentes ainda hoje no Brasil. Em 1959 foi fundado o Centro de Estudos AfroOrientais (CEAO) junto à UFBA; em 1961 o Instituto Brasileiro de Estudos Afro-Asiáticos (IBEAA) ligado à presidência da República, fechado com o golpe militar; em 1963, o Centro de Estudos e Cultura Africana junto à FFLCH/USP, hoje denominado Centro de Estudos Africanos (CEA) e em 1973 o Centro de Estudos Afro-Asiáticos (CEAA) do Rio de Janeiro, uma espécie de herdeiro do IBEAA. (Zamparoni 1995, p. 116).
}

Os governos militares se aproximaram da África, mas a tese principal sustentada é que os interesses (neo)colonialistas orientavam os interesses brasileiros na África. Isto é sustentado sobretudo por Honório Rodrigues (Zamparoni, 1995), mas também por outros, e não teve início somente nos governos militares, mas também no germe da Política Externa Independente, ainda no governo Quadros --- documentos organizados em Rodrigues (1982) apresentam a crítica ao discurso colonialista das relações brasileiras com a África e a necessidade de desconstrui-las, algo que endossamos aqui.

Quer dizer, não bastam que sejam os interesses econômicos ou geopolíticos. Mas eles são fundamentais para permitir que as políticas públicas de defesa e política externa recoloquem novamente Cabo Verde no espectro. Só com o governo Lula esse interesse voltou a ser tão acentuado que recolocou a África os objetivos estratégicos do país. Nossa cooperação com a Nigéria, com a Namíbia, com o Zimbábue, com a África do Sul e com os países da lusofonia ficou inegavelmente mais forte e isto coadunava-se com o papel internacional que queríamos exercer naquele momento - chamávamos aquilo de diplomacia ativa e altiva (Amorim, 2013). 
Os tempos da altivez e da atitude parecem ter ficado num passado que agora parece muito distante. No entanto os laços continuam lá e não se perdem facilmente.

Com Cabo Verde não deveria ser diferente. Seu papel geograficamente estratégico deveria fazer do arquipélago um ponto nevrálgico de interesse do Brasil, como outras potências costumam fazer uso das ilhas, seja para reabastecimento, ou como hub aéreo, entre outros. Devemos lembrar que há muitas Ilhas no Atlântico que pertencem a potências estrangeiras como França e Inglaterra e que de forma estratégica estar próximo de Cabo Verde significa ter uma posição importante no meio desse mar assado de presença estrangeira na região.

Se é nosso objetivo transformar o Atlântico Sul numa zona de fato de paz, Cabo Verde deveria estar no topo das nossas preocupações assim como a presença estrangeira na região. Passa, portanto, ao largo da cooperação meramente econômica, e é mais uma visão de alcance maior e que deveria transpor as relações partidárias que contaminam tanto a política nacional.

Cabo Verde poderia ser a chave brasileira no Atlântico. Poderia ser hub, aéreo, militar, comercial. O potencial ali existente é latente, mas precisa ser explorado por uma diplomacia que perceba a importância de África em nossa política externa. É um país de intensa produção cultural, de instituições políticas cada vez mais sólidas, que necessita de uma ajuda que não custaria caro aos cofres públicos e que teria retorno fácil.

\section{REFERÊNCIAS BIBLIOGRÁFICAS}

Amorim, C. (2013). Breves narrativas diplomáticas. São Paulo, Benvirá.

Lechini, G. (2003). A política exterior Argentina para África no marco referencial da Política Africana para o Brasil: o caso da África do Sul na década de 1990. Tese de doutorado. Universidade de São Paulo, São Paulo.

Lobbann, R. e Lopes, M. (1995). Historical dictionary of the Republic of Cape Verde. Library of Congress, Washington.

Meintel, D. (2002). Cape Verdean Transnationalism, Old and New. Anthropologica, 44(1), pp. 25-42, JSTOR, www.jstor.org/stable/25606058.

Pereira, D. A. (2011). Das relações históricas Cabo Verde-Brasil. Brasília, Funag.

Pereira, J. A. (2015). O PAIGC perante o dilema Cabo-verdiano. Documentos, Lisboa. 
Reis, A.; Rezola, M. e Santos, P. (coord.). (2016). Dicionário de História de Portugal: o 25 de abril. V. 2. Figueirinhas, Lisboa.

Rodrigues, J. H. (1982). Brasil e África. Outro Horizonte. São Paulo, Nova Fronteira.

Santos, B. de S. (2015). A Justiça Popular em Cabo Verde. Almedina, Coimbra.

Saraiva, J. F. S. (2002). Política exterior do governo Lula: o desafio africano. Revista Brasileira de Política Internacional [online], 45. Disponível em: http://www.scielo.br/pdf/rbpi/v45n2/a01v45n2.pdf

Silva, B. (1956). Cabo Verde visto por Gilberto Freyre - apontamentos lidos ao microfone da Rádio Barlavento. Boletim de Propaganda e Informação. Praia, Imprensa Nacional.

Tavares, A. J. C, (2013). Cabo Verde e os desafios da política internacional contemporânea. Revista Estudos Políticos: a publicação eletrônica semestral do Laboratório de Estudos Hum(e)anos (UFF) e do Núcleo de Estudos em Teoria Política (UFRJ). Rio de Janeiro, no 7, pp. 211 - 235, dezembro. Disponível em: http://revistaestudospoliticos.com/.

Zamparoni, Valdemir, (1995). Os estudos africanos no Brasil: veredas. Revista de Educação Pública, 4(5), pp. 105-124. 